\title{
EFICIÊNCIA E DIVERSIDADE FENOTÍPICA DE BACTÉRIAS DIAZOTRÓFICAS QUE NODULAM CAUPI [Vigna unguiculata (L.) WALP] E FEIJOEIRO (Phaseolus vulgaris L.) EM SOLOS DE MINERAÇÃO DE BAUXITA EM REABILITAÇÃ̃O ${ }^{(1)}$
}

\author{
Rogério Melloni $^{(2)}$, Fátima Maria de Sousa Moreira ${ }^{(3)}$, Rafaela Simão \\ Abrahão Nóbrega ${ }^{(4)} \&$ José Oswaldo de Siqueira ${ }^{(3)}$
}

\begin{abstract}
RESUMO
A atividade de mineração provoca degradação ambiental em várias partes do mundo, e técnicas de revegetação, empregando diversas espécies vegetais, têm sido indicadas, com vistas em reabilitar essas áreas. A eficiência e a diversidade de grupos-chave de bactérias, como as que nodulam leguminosas e fixam $\mathrm{N}_{2}$ (BNLFN), são de extrema importância, uma vez que estas participam de processos de ciclagem de nutrientes e contribuem para a sustentabilidade dessas áreas. Com o objetivo de avaliar a eficiência e a diversidade de BNLFN, coletaram-se amostras de solo de áreas mineradas, sob diferentes estratégias e cronosseqüências de reabilitação, no verão de 1999, para instalação de ensaios, empregando feijoeiro e caupi como espécies de plantas-isca de BNLFN. Na floração, coletaram-se as plantas e avaliaram-se matéria seca da parte aérea, número, matéria fresca e atividade de nódulos. Não houve influência das diferentes estratégias de reabilitação na eficiência das populações de BNLFN no crescimento do feijoeiro. A diversidade fenotípica dos isolados de BNLFN foi avaliada por meio das características culturais destes em meio de cultivo 79. Após a caracterização fenotípica de 328 isolados de feijoeiro e 420 de caupi, verificou-se que este é mais indicado que o feijoeiro nos estudos de nodulação, eficiência e diversidade de BNLFN. O impacto negativo da
\end{abstract}

\footnotetext{
(1) Parte da Tese de Doutorado do primeiro autor, apresentada ao curso de Pós-Graduação em Solos e Nutrição de Plantas do Departamento de Ciência do Solo, Universidade Federal de Lavras - DCS/UFLA. Trabalho financiado pelo convênio FAEPE/ALCOA e FAPEMIG. Recebido para publicação em maio de 2004 e aprovado em fevereiro de 2006.

(2) Professor do Instituto de Recursos Naturais - UNIFEI. Caixa Postal 50, CEP 37500-903 Itajubá (MG). E-mail: rmelloni@unifei.edu.br

(3) Professor do Departamento de Ciência do Solo, Universidade Federal de Lavras - DCS/UFLA. Caixa Postal 37, CEP 37200-000 Lavras (MG). Bolsista CNPq. E-mail: fmoreira@ufla.br; siqueira@ufla.br

(4) Doutoranda do curso de PGSNP/DCS/UFLA. Bolsista do CNPq. E-mail: rafaelanobrega@ufla.br
} 
mineração é maior na diversidade fenotípica cultural de BNLFN do que na nodulação das plantas-isca utilizadas. A revegetação contribuiu para aumentar a diversidade dessas bactérias em solos de áreas de mineração de bauxita, especialmente quando ocorreu a introdução de leguminosas.

Termos de indexação: simbiontes radiculares, solo degradado, planta-isca, rizóbio.

\author{
SUMMARY: EFFICIENCY AND PHENOTYPIC DIVERSITY AMONG \\ NITROGEN-FIXING BACTERIA THAT NODULATE COWPEA \\ [Vigna unguiculata (L.) WALP] AND COMMON BEAN \\ (Phaseolus vulgaris L.) IN BAUXITE-MINED SOILS UNDER \\ REHABILITATION
}

\begin{abstract}
Mining activities promote severe environmental degradation in many parts of the world, and revegetation techniques with diverse plant species have been used for rehabilitation of these areas. Studies on the occurrence, efficiency and diversity of key microbial groups such as leguminosae-nodulating, nitrogen fixing bacteria (LNNFB) are essential because they are involved in nutrient cycling processes and, therefore, to the sustainability of these areas. Aiming to evaluate the efficiency and phenotypic diversity of $L N N F B$, soil samples were collected from different bauxite mining areas with distinct rehabilitation strategies and chronosequences in the summer of 1999. With these materials we installed experiments using bean and cowpea as trap species under greenhouse conditions. At flowering, the plants were harvested and the shoot dry weight, nodule number, nodule weight, nitrogenase activity, and phenotypic diversity of LNNFB isolates evaluated by culture characterization on 79 medium. There was no influence of the different rehabilitation strategies on the efficiency of LNNFB populations in promoting bean growth. After phenotypic characterization of 328 bean and 420 cowpea LNNFB isolates, it was found that the latter is better suited than bean for studies evaluating LNNFB nodulation, efficiency and diversity in these areas. Mining strongly decreases the LNNFB diversity, while there is little effect on nodulation of trap plants. Rehabilitation strategies contribute to increase LNNFB diversity in bauxite mined soils, mainly when legume species were introduced.
\end{abstract}

Index terms: root symbiosis, disturbed soil, trap plants, rhizobia.

\section{INTRODUÇÃO}

As atividades de mineração estão entre as principais responsáveis pela degradação dos solos em todo mundo (Dias \& Gryffith, 1998), além de causar uma inevitável alteração na paisagem, decorrente dos processos de exploração. Dessa forma, medidas para a reabilitação das áreas degradadas pela mineração devem ser eficazes e realizadas com vistas em acelerar a sucessão natural. Com este propósito, a revegetação tem sido a principal prática para recompor e proteger o solo, evitar a poluição das águas e promover o retorno da vida selvagem (Melo et al., 2000) e da biota edáfica (Melloni et al., 2003, 2004), além de incrementar a sucessão vegetal, contribuindo, conseqüentemente, para o fluxo de energia e nutrientes nos ecossistemas (Siqueira et al., 1994).

Uma das limitações para a revegetação de áreas mineradas é a fertilidade do solo ou do substrato, sendo o nitrogênio considerado um dos nutrientes mais limitantes para o crescimento vegetal.
Portanto, uma importante forma de disponibilizar o nitrogênio, em áreas sob mineração de bauxita, é a utilização de espécies vegetais capazes de efetuar simbiose com bactérias que nodulam leguminosas e fixam $\mathrm{N}_{2}$ atmosférico (BNLFN) (Franco \& Faria, 1997). A maior diversidade de BNLFN pode favorecer a simbiose com várias espécies leguminosas e maximizar a fixação biológica do nitrogênio em áreas degradadas. Além disso, quanto maior a diversidade de espécies, maior a resiliência dos processos microbianos do solo.

As populações de BNLFN nativas de áreas degradadas pela mineração estão, provavelmente, mais adaptadas às condições edáficas e ambientais locais. No entanto, não há registros de levantamentos da ocorrência, diversidade e eficiência de populações de BNLFN, em solos de mineração de bauxita no Brasil e no mundo.

Um dos métodos mais utilizados para avaliar a diversidade de BNLFN nos solos é a utilização de plantas-isca, cuja principal característica é a promiscuidade, ou seja, devem ser capazes de nodular com 
uma grande diversidade de espécies. Dentre as espécies de leguminosas consideradas promíscuas, podem-se destacar o caupi (Vigna unguiculata) e o feijoeiro (Phaseolus vulgaris) (Lewin et al., 1987; Martins et al., 1997). Sendo estas espécies de importância econômica na alimentação humana, o estudo da diversidade de bactérias fixadoras de nitrogênio que as nodulam tem adicional importância.

O objetivo deste trabalho foi avaliar a eficiência e a diversidade fenotípica de populações de BNLFN em solos de áreas de mineração de bauxita, sob diferentes estratégias e cronosseqüências de reabilitação, utilizando feijoeiro e caupi como espécies de plantas-isca.

\section{MATERIAL E MÉTODOS}

O presente estudo foi realizado em áreas da ALCOA Alumínio S/A, Poços de Caldas, Minas Gerais, em dois ambientes distintos, de campo e serra. De acordo com o histórico quanto à estratégia e estádio de reabilitação, e tipo de solo, selecionaram-se 17 áreas em Cambissolo distrófico para as amostragens. Foram selecionadas oito áreas no campo, com vegetação original típica de campo tropical, compostas por espécies herbáceas e arbustivas, e nove áreas na serra, mais montanhosas e com cobertura vegetal original tipo capoeira e mata. As áreas mineradas foram reabilitadas mediante a semeadura de gramíneas e leguminosas herbáceas, plantios de mudas de bracatinga (Mimosa scabrella), espécies arbóreas nativas e de Eucalyptus saligna Smith, estando todas as áreas com diferentes idades de reabilitação, em relação à área de referência, que não sofreu alteração antrópica (Quadro 1).

As amostras de solo de cada área foram coletadas no verão, dentro de três transectos de 4 x $25 \mathrm{~m}$, na profundidade de $0-10 \mathrm{~cm}$, num total de três amostras compostas por área, formadas por dez subamostras cada. Cada área foi considerada um tratamento com três repetições formadas por dez amostras compostas. Os teores de matéria orgânica das áreas amostradas também se encontram no quadro 1.

Com as amostras compostas de solo coletadas, foram instalados dois experimentos em casa de vegetação, ambos dispostos em delineamento inteiramente ao acaso, tendo um experimento utilizado o feijoeiro cv. Carioca (Phaseolus vulgaris L.) e outro caupi cv. Mulato (Vigna unguiculata L. Walp) como espécies de plantas-isca de BNLFN. Amostras de solo de cada área foram colocadas em vasos de PVC, revestidos com sacos plásticos pretos de $1 \mathrm{~L}$ (1,25 kg de amostra de solo). As sementes foram desinfestadas superficialmente antes do plantio utilizando álcool $70 \%$ por $3 \mathrm{~min}$, hipoclorito de sódio $1 \%$ por 3 min e lavagens sucessivas em água corrente (Andrade \& Hamakawa, 1994). Todas as amostras de solo foram corrigidas com calcário dolomítico (14 \% MgO, 35 \% CaO e PRNT 100 \%), para elevar a saturação por bases a $70 \%$, e adubadas com $50 \mathrm{mg} \mathrm{kg}{ }^{-1}$ de $\mathrm{P}-\mathrm{KH}_{2} \mathrm{PO}_{4}, 100 \mathrm{mg} \mathrm{kg}{ }^{-1}$ de $\mathrm{K}-\mathrm{K}_{2} \mathrm{SO}_{4}$, $15 \mathrm{mg} \mathrm{kg}^{-1}$ de $\mathrm{S}-\mathrm{K}_{2} \mathrm{SO}_{4}, 0,1 \mathrm{mg} \mathrm{kg}^{-1}$ de $\mathrm{Mo-}$ $\mathrm{HMoO}_{4} \cdot \mathrm{H}_{2} \mathrm{O}, 5 \mathrm{mg} \mathrm{kg}-1$ de $\mathrm{Zn}-\mathrm{ZnSO}_{4} \cdot 7 \mathrm{H}_{2} \mathrm{O}, 1,5 \mathrm{mg} \mathrm{kg}{ }^{-1}$ de $\mathrm{Cu}-\mathrm{CuCl}_{2} \cdot 2 \mathrm{H}_{2} \mathrm{O}$, e $0,5 \mathrm{mg} \mathrm{kg}{ }^{-1}$ de $\mathrm{B}-\mathrm{H}_{3} \mathrm{BO}_{3}$. A correção dos atributos químicos teve por objetivo eliminar efeitos limitantes da fertilidade do solo sobre o crescimento e nodulação das culturas avaliadas.

Nos dois experimentos, manteve-se uma planta por vaso e, na floração, após 47 dias da semeadura, coletaram-se as plantas para determinação da matéria seca da parte aérea, matéria fresca, número e atividade da nitrogenase dos nódulos, por meio de leitura de redução de acetileno em cromatógrafo a gás Varian Star 3400CX (Dilworth, 1966). Os dados foram submetidos à análise de variância pelo teste $\mathrm{F}$, com comparação de médias por Duncan a $5 \%$ de significância, enquanto os valores obtidos de número de nódulos por planta receberam transformação raiz quadrada de $\mathrm{x}+0,5$, antes da análise estatística pelo programa SANEST (Zonta et al., 1984). Fez-se análise de correlação entre matéria orgânica, variáveis de crescimento e de nodulação de ambas as espécies de plantas-isca, sendo apresentadas somente aquelas significativas estatisticamente.

Após a pesagem dos nódulos frescos, procedeuse ao isolamento de BNLFN. Para isso, os nódulos (mínimo de 10 por planta) foram desinfestados superficialmente com álcool $95 \%$, cloreto de mercúrio 0,1 \% e lavagens sucessivas em água esterilizada, antes da maceração e riscagem das estrias, sob condições assépticas em meio de cultura 79 (Fred \& Waksman, 1928). As características culturais avaliadas foram: tempo, em dias, para visualização das colônias; diâmetro médio das colônias; modificação do pH do meio; produção de goma e coloração das colônias. Com exceção da característica tempo, em dias, para visualização das colônias, as demais foram avaliadas após 5, 8, 12 e 15 dias de aparecimento das colônias para, respectivamente, os isolados de crescimento rápido, intermediário, lento e muito lento.

Os fenótipos culturais dos isolados foram comparados com as características das estirpes-tipo e referência de Rhizobium leguminosarum bv. phaseoli (ER 316ci0a) e trifolii (NZP 1), R. etli $\left(\mathrm{CFN} 42^{\mathrm{T}}\right)$, R. tropici (CIAT 899 $\left.{ }^{\mathrm{T}}\right), R$. galegae bv. orientalis (HAMBI 540 ${ }^{\mathrm{T}}$ ), Bradyrhizobium japonicum (ATCC $10324^{\mathrm{T}}$ ), B. elkanii (BR 29), Sinorhizobium meliloti (NZP 4027 T), S. fredii cv. fredii (USDA 205 ${ }^{\mathrm{T}}$ ), S. medicae (A $\left.321^{\mathrm{T}}\right)$, S. saheli (ORS 609 $\left.{ }^{\mathrm{T}}\right)$, S. terangae (USDA $\left.4894^{\mathrm{T}}\right)$, Mesorhizobium loti (NZP 2213 $\left.{ }^{\mathrm{T}}\right), M$. plurifarum (BR 3804), M. ciceri (UPM-Ca7 ${ }^{\mathrm{T}}$ ), $M$. huakuii (CCBAU 2609 $\left.{ }^{\mathrm{T}}\right)$, M. tianshiense $\left(\mathrm{A}-1 \mathrm{BS}^{\mathrm{T}}\right)$, M. mediterraneum (UPM-Ca36 ${ }^{\mathrm{T}}$ ), Azorhizobium caulinodans (ORS571 ${ }^{\mathrm{T}}$ ) e Alorhizobium undicola $\left(\right.$ ORS $\left.992^{\mathrm{T}}\right)$. 
Quadro 1. Características principais das áreas amostradas, em dois ambientes (campo e serra), de solos minerados com diferentes teores de matéria orgânica e condições de reabilitação

\begin{tabular}{|c|c|c|c|c|c|}
\hline Área & $\begin{array}{l}\text { Localização } \\
\text { da mina }\end{array}$ & Característica principal & $\begin{array}{c}\text { Teor } \\
\text { de } \text { MO }^{(1)}\end{array}$ & $\operatorname{Idade}^{(2)}$ & Tamanho \\
\hline & & & dag kg-1 & & ha \\
\hline \multicolumn{6}{|l|}{ Campo } \\
\hline $\mathrm{RM}$ & Morro das Árvores & $\begin{array}{l}\text { Recém-minerada, coberta por braquiária (Brachiaria } \\
\text { decumbens) e feijão-guandu (Cajanus cajan) }\end{array}$ & 3,23 & 6 meses & 4,98 \\
\hline E3 & José Gabriel & Plantio homogêneo de eucalipto (Eucalyptus saligna) (E) & 3,73 & 3 anos & 4,22 \\
\hline $\mathrm{AE} 4$ & Morro das Árvores II & $\begin{array}{l}\text { Capim-azevém (Lolium multiflorum) (A) e Eupathorium sp. } \\
\text { (Asteraceae) (E) }\end{array}$ & 3,90 & 4 anos & 1,33 \\
\hline GB10 & Morro das Árvores II & $\begin{array}{l}\text { Capim-gordura (Melinis minutiflora) (G), em sucessão. } \\
\text { Presença de espécies nativas como bracatinga (B) }\end{array}$ & 3,87 & 10 anos & 1,90 \\
\hline E16 & Cabeça de Boi & Eucalipto (E. saligna) (E) e serapilheira espessa & 5,10 & 16 anos & 4,69 \\
\hline BG19 & Morro das Árvores II & $\begin{array}{l}\text { Bracatinga (Mimosa scabrella) (B) e sub-bosque bem } \\
\text { desenvolvido (capim-gordura, alecrim) }\end{array}$ & 6,33 & 19 anos & 1,73 \\
\hline $\mathrm{RF}$ & Morro das Árvores II & $\begin{array}{l}\text { Referência ( } \mathrm{RF}) \text {, com espécies graminóides e arbustivas } \\
\text { (sem alteração antrópica) }\end{array}$ & 3,50 & n.d. & 11,00 \\
\hline \multicolumn{6}{|l|}{ Serra } \\
\hline $\mathrm{RM}$ & Cabeça de Boi & $\begin{array}{l}\text { Recém-minerada (RM). Coberta por capim-gordura, feijão- } \\
\text { guandu e espécies arbóreas nativas }\end{array}$ & 3,50 & 6 meses & 4,85 \\
\hline FGb2 & Retiro Branco & $\begin{array}{l}\text { Feijão-guandu (FG), braquiária (b) e espécies arbóreas } \\
\text { nativas }\end{array}$ & 1,17 & 2 anos & n.d. \\
\hline GB6 & Retiro Branco & $\begin{array}{l}\text { Bracatinga }(B) \text { e sub-bosque coberto predominantemente } \\
\text { por capim-gordura }\end{array}$ & 3,93 & 6 anos & 2,55 \\
\hline M10 & Santa Rosália & $\begin{array}{l}\text { Mata de espécies nativas }(\mathrm{M}) \text { e sub-bosque bem } \\
\text { desenvolvido, com serapilheira adicionada }\end{array}$ & 4,57 & 10 anos & 2,18 \\
\hline B14 & Retiro Branco & $\begin{array}{l}\text { Bracatinga (B) e vegetação rasteira e arbustiva, processo } \\
\text { de sucessão lento }\end{array}$ & 4,83 & 14 anos & 8,89 \\
\hline E16 & Retiro Branco & $\begin{array}{l}\text { Eucalipto (E. saligna) (E) e sub-bosque bem desenvolvido } \\
\text { (gramíneas e arbustos) }\end{array}$ & 6,73 & 16 anos & 17,42 \\
\hline M18 & Retiro Branco & $\begin{array}{l}\text { Mata de espécies nativas (M), incluindo bracatinga, sub- } \\
\text { bosque fechado, serapilheira espessa, troncos caídos }\end{array}$ & 6,97 & 18 anos & 3,85 \\
\hline $\mathrm{RF}$ & Retiro Branco & $\begin{array}{l}\text { Referência (RF), mata fechada com espécies arbóreas (sem } \\
\text { alteração antrópica) }\end{array}$ & 7,63 & n.d. & 57,23 \\
\hline
\end{tabular}

${ }^{(1)}$ Matéria orgânica. ${ }^{(2)}$ Idade aproximada de reabilitação em março de 1999. n.d. = não-disponível.

Após a caracterização cultural de todos os isolados e de estirpes-tipo e referência, foram construídos dois dendrogramas de similaridade, para o estudo de diversidade, sendo um para os isolados de caupi e outro para os de feijoeiro, pelo método Complete Linkage e Distância Euclidiana (Everitt, 1993), por meio do programa STATISTICA 5.0 (1995). Para isso, foram atribuídos valores ponderados de acordo com a importância atribuída às características culturais apresentadas pelos isolados e estirpes-tipo e referência, sendo de 100, 75, 100, 25 e $75 \%$, respectivamente, para as características tempo, em dias, para visualização das colônias; diâmetro da colônia; alteração do pH do meio; produção de goma e coloração da colônia (Quadro 2). As características culturais tempo de aparecimento da colônia e alteração do pH do meio foram utilizadas para a separação de gêneros de Rhizobiaceae (Jordan, 1984), sendo consideradas as mais discriminantes. Já para as demais características, os valores estipulados refletem a experiência do grupo em trabalhos anteriores já publicados (Moreira, 1991; Moreira et al., 1993). 
Quadro 2. Valores relativos às características culturais dos isolados e estirpes-tipo ou referência de rizóbios utilizados na construção dos dendrogramas de similaridade

\begin{tabular}{|c|c|c|}
\hline Característica cultural & Intervalo de observação & $\begin{array}{l}\text { Valor atribuído para } \\
\text { a construção dos } \\
\text { dendrogramas }{ }^{(2)}\end{array}$ \\
\hline \multirow[t]{5}{*}{ 1. Tempo, em dias, para visualização das colônias } & 1 dia (muito rápido) & 1 \\
\hline & 2 a 3 dias (rápido) & 2 \\
\hline & 4 a 5 dias (intermediário) & 3 \\
\hline & 6 a 10 dias (lento) & 4 \\
\hline & $>10$ dias (muito lento) & 5 \\
\hline \multirow{3}{*}{ 2. Diâmetro da colônia (1) } & $<1 \mathrm{~mm}$ & 1 \\
\hline & 1 a $2 \mathrm{~mm}$ & 2 \\
\hline & $>2 \mathrm{~mm}$ & 3 \\
\hline \multirow[t]{3}{*}{ 3. Alteração do pH do meio (1) } & Acidificante & 1 \\
\hline & Neutro & 2 \\
\hline & Alcalinizante & 3 \\
\hline \multirow[t]{4}{*}{ 4. Produção de goma (1) } & Seca & 1 \\
\hline & Baixa & 2 \\
\hline & Média & 3 \\
\hline & Alta & 4 \\
\hline \multirow[t]{2}{*}{ 5. Coloração da colônia (1) } & Branca & 1 \\
\hline & Amarela & 2 \\
\hline
\end{tabular}

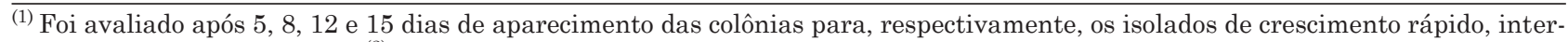
mediário, lento e muito lento. ${ }^{(2)}$ Os valores foram ponderados de acordo com a importância atribuída às características culturais no estudo de diversidade, sendo de 100, 75, 100, 25 e $75 \%$, respectivamente, para as características $1,2,3,4$ e 5 .

Com os grupos culturais obtidos, procedeu-se à construção dos dendrogramas e ao cálculo do índice de diversidade de Shannon-Weaver (Shannon \& Weaver, 1949) para as diferentes áreas de estudo, conforme a equação:

$$
\mathrm{H}^{\prime}=-\sum_{\mathrm{i}=1}^{\mathrm{K}} \mathrm{pi} \ln \mathrm{pi} \text {, onde }
$$

$\mathrm{H}^{\prime}=$ índice de diversidade de Shannon-Weaver

$\mathrm{k}$ = número de grupos formados com as diferentes características culturais, pi = abundância relativa dos isolados em cada grupo.

\section{RESULTADOS E DISCUSSÃO}

\section{Matéria seca da parte aérea (MSPA), nodulação e atividade da nitrogenase}

Não houve efeito das estratégias de reabilitação na eficiência das populações de BNLFN do feijoeiro, indicada pela MSPA, tanto para campo como para serra, com exceção da área recém-minerada na serra, que apresentou o menor valor para esta variável (Quadro 3). Já a MSPA de caupi variou de 1,90 a

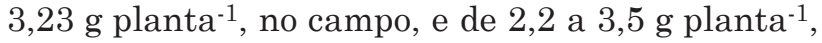
na serra, havendo diferenças significativas no comportamento desta espécie, quando cultivada em amostras de solos dos diferentes tratamentos. Nos dois ambientes, campo e serra, as populações das áreas recém-mineradas foram as menos eficientes e, de modo geral, as mais eficientes foram aquelas oriundas das áreas com maior tempo de reabilitação, principalmente na serra. Exceção a esta tendência foi o eucalipto com 16 anos (E16) no campo e sem sub-bosque onde as populações foram ineficientes, fato este não observado para o eucalipto com a mesma idade na serra, mas com sub-bosque bem desenvolvido. Entretanto, na área de referência (RF) da serra, o maior valor de MSPA não pode ser explicado pela eficiência das populações de BNLFN, porque não houve nodulação neste tratamento, mas, sim, pelo alto teor de matéria orgânica no solo que foi de 7,63 dag $\mathrm{kg}^{-1}$ (Quadro 1).

É bem documentada a inibição da nodulação por altos teores de matéria orgânica e de N-mineral. Contudo, não foram registradas correlações significativas entre matéria orgânica do solo e as variáveis de nodulação (número e matéria fresca de 
Quadro 3. Matéria seca da parte aérea (MSPA), e número ( No. $^{\circ}$, matéria fresca (MF) e atividade da nitrogenase em nódulos, obtidos de feijoeiro e caupi, cultivados em amostras de solos de áreas de mineração de bauxita em reabilitação

\begin{tabular}{|c|c|c|c|c|c|c|c|c|}
\hline \multirow{2}{*}{ Área(1) } & \multicolumn{2}{|c|}{ MSPA } & \multicolumn{2}{|c|}{ No de nódulos } & \multicolumn{2}{|c|}{ MF de nódulo } & \multicolumn{2}{|c|}{$\begin{array}{c}\text { Atividade da } \\
\text { nitrogenase }\end{array}$} \\
\hline & Feijoeiro & Caupi & Feijoeiro & Caupi & Feijoeiro & Caupi & Feijoeiro & Caupi \\
\hline & \multicolumn{2}{|c|}{ g planta-1(2) } & \multicolumn{2}{|c|}{$\mathrm{n}^{0}$ planta $^{-1}\left(2^{\prime}\right)$} & \multicolumn{2}{|c|}{ mg planta-1 (2) } & \multicolumn{2}{|c|}{ nmol $\mathrm{C}_{2} \mathrm{H}_{4} \mathrm{~h}^{-1}$ planta- $^{-1(2)}$} \\
\hline \multicolumn{9}{|l|}{$\mathrm{Campo}^{(3)}$} \\
\hline RM 0,5 & $1,16 \mathrm{a}$ & $2,03 \mathrm{c}$ & $16,3 \mathrm{ab}$ & 39,6 a & $227 \mathrm{abc}$ & $758 \mathrm{abc}$ & $413 \mathrm{~b}$ & $386 \mathrm{bcd}$ \\
\hline E3 & $1,67 \mathrm{a}$ & $2,29 \mathrm{bc}$ & $39,3 \mathrm{a}$ & $61,6 \mathrm{a}$ & $281 \mathrm{ab}$ & $712 \mathrm{bc}$ & $2.400 \mathrm{a}$ & $719 \mathrm{~b}$ \\
\hline $\mathrm{AE} 4$ & $1,00 \mathrm{a}$ & $1,90 \mathrm{c}$ & $4,7 \mathrm{~b} \mathrm{c}$ & $37,6 \mathrm{a}$ & $79 \mathrm{bc}$ & $762 \mathrm{abc}$ & $685 \mathrm{~b}$ & $468 \mathrm{bcd}$ \\
\hline GB10 & 0,99 a & $2,63 \mathrm{abc}$ & $28,3 \mathrm{a}$ & $61,7 \mathrm{a}$ & $325 \mathrm{ab}$ & $902 \mathrm{a}$ & $420 \mathrm{~b}$ & $567 \mathrm{bc}$ \\
\hline E16 & $1,62 \mathrm{a}$ & $1,95 \mathrm{c}$ & 0 & $34,0 \mathrm{a}$ & 0 & $687 \mathrm{c}$ & 0 & $249 \mathrm{~cd}$ \\
\hline BG19 & $1,38 \mathrm{a}$ & $3,01 \mathrm{ab}$ & $41,8 \mathrm{a}$ & $55,1 \mathrm{a}$ & $311 \mathrm{ab}$ & $828 \mathrm{abc}$ & $521 \mathrm{~b}$ & $164 \mathrm{~d}$ \\
\hline $\mathrm{RF}$ & $1,47 \mathrm{a}$ & 3,23 a & 47,9 a & 61,4 a & $427 \mathrm{a}$ & $884 a b$ & $812 \mathrm{~b}$ & $1.304 \mathrm{a}$ \\
\hline CV (\%) & 27,6 & 17,8 & 34,9 & 14,8 & 59,2 & 12,0 & 63,8 & 35,2 \\
\hline \multicolumn{9}{|l|}{ Serra $^{(3)}$} \\
\hline RM 0,5 & $0,95 \mathrm{~b}$ & $2,2 \mathrm{c}$ & $7,5 \mathrm{~d}$ & $31,8 \mathrm{~b}$ & $189 \mathrm{c}$ & $650 \mathrm{ab}$ & 0 & $929 a b$ \\
\hline FGb2 & $1,93 \mathrm{a}$ & $2,54 \mathrm{bc}$ & $55,1 \mathrm{bc}$ & $53,5 \mathrm{ab}$ & $606 \mathrm{a}$ & $189 a b$ & $324 \mathrm{ab}$ & $613 \mathrm{ab}$ \\
\hline GB6 & $2,31 \mathrm{a}$ & $2,34 \mathrm{c}$ & $124,8 \mathrm{a}$ & $56,7 \mathrm{ab}$ & $682 \mathrm{a}$ & $1.086 \mathrm{a}$ & $450 \mathrm{a}$ & $659 \mathrm{ab}$ \\
\hline M10 & $2,01 \mathrm{a}$ & $2,42 \mathrm{c}$ & $70,2 \mathrm{bc}$ & $47,7 \mathrm{ab}$ & $411 \mathrm{~b}$ & $802 \mathrm{ab}$ & $466 \mathrm{a}$ & $447 \mathrm{ab}$ \\
\hline B14 & $1,90 \mathrm{a}$ & 3,46 a & $36,7 \mathrm{c}$ & $38,8 \mathrm{ab}$ & $49 \mathrm{~d}$ & $508 \mathrm{~b}$ & 0 & $924 \mathrm{ab}$ \\
\hline E16 & $1,87 \mathrm{a}$ & $3,4 \mathrm{ab}$ & $86,4 \mathrm{ab}$ & $53,5 \mathrm{ab}$ & $717 \mathrm{a}$ & $468 \mathrm{~b}$ & $68 \mathrm{bc}$ & $249 \mathrm{~b}$ \\
\hline M18 & $2,35 \mathrm{a}$ & $3,5 \mathrm{a}$ & $123,0 \mathrm{a}$ & $46,7 \mathrm{ab}$ & $598 \mathrm{a}$ & $653 a b$ & 0 & $566 \mathrm{ab}$ \\
\hline $\mathrm{RF}$ & $2,18 \mathrm{a}$ & $3,08 \mathrm{abc}$ & 0 & $70,6 \mathrm{a}$ & 0 & $633 \mathrm{~b}$ & 0 & $1371 \mathrm{a}$ \\
\hline CV (\%) & 20,0 & 17,2 & 18,1 & 18,5 & 18,7 & 32,5 & 90,8 & 48,5 \\
\hline
\end{tabular}

(1) Campo: RM reabilitada com braquiária e feijão-guandu; E3 eucalipto três anos; AE4 capim-azevém e Eupathorium sp. quatro anos; GB10 capim-gordura e bracatinga; E16 eucalipto; BG19 bracatinga e capim-gordura; RF referência, sem alterações antrópicas. Serra: RM reabilitada com capim-gordura e feijão-guandu; FGb2 feijão-guandu, braquiária; GB6 bracatinga e sub-bosque coberto predominantemente por capim-gordura; M10 espécies nativas; B14 bracatinga; E16 eucalipto; M18 bracatinga e espécies nativas; RF referência. ${ }^{(2)}$ Médias seguidas por letras distintas, na coluna, diferem estatisticamente por Duncan a 5 \%. ${ }^{(3)}$ Os números após as letras indicam anos após o plantio das espécies.

nódulos e atividade de nitrogenase) de feijoeiro ou caupi, no campo e serra, indicando que os resultados obtidos foram devidos às diferenças de comportamento das plantas-isca mediante as estratégias estudadas.

Quanto às variáveis relacionadas com a nodulação, as plantas-isca também se comportaram distintamente, nos dois ambientes. Já o caupi, ao contrário do que ocorreu na MSPA, não mostrou diferença nas amostras de diferentes áreas do campo para número de nódulos, e nas amostras oriundas da serra, foram observadas poucas diferenças. Analisando o número de nódulos do feijoeiro, os maiores valores obtidos não estavam necessariamente relacionados com a presença de leguminosas nas áreas mineradas em processos de realibilitação. Para matéria fresca e atividade da nitrogenase dos nódulos houve diferenças entre os tratamentos, tanto para feijoeiro como para caupi, no campo e na serra.
Houve correlações significativas, somente para caupi, entre MSPA e número $\left(r=0,78^{*}\right)$ ou matéria fresca de nódulos $\left(\mathrm{r}=0,78^{*}\right)$ de plantas cultivadas em amostras de solo das áreas do campo, e entre MSPA e matéria fresca $\left(r=0,71^{*}\right)$ ou atividade de nódulos $\left(r=0,95^{* *}\right)$ de plantas cultivadas em amostras de solo da serra, evidenciando a presença de populações de BNLFN eficientes para esta espécie nos dois ambientes. A ineficiência de populações que nodulam o feijoeiro foi corroborada, não só pela ausência de efeito dos tratamentos sobre a MSPA, embora houvesse populações variáveis, mas também pela ausência de atividade da nitrogenase dos nódulos das amostras dos seguintes locais do ambiente de serra: área recém-minerada com seis meses de reabilitação (RM), plantio de bracatinga e vegetação rasteira e arbustiva com 14 anos de reabilitação (B14) e área de mata nativa com 18 anos de reabilitação (M18). 
Além disso, as populações de BNLFN foram ausentes nas áreas que tinham eucalipto há 16 anos (E16), no campo, e na área de mata fechada sem alteração antrópica (RF), na serra. A nodulação observada em áreas recém-mineradas e revegetadas há apenas seis meses, RM, no campo, e RM, na serra, indica que as populações de BNLFN puderam-se manter viáveis e com capacidade de estabelecer simbiose com plantas, quando as condições ambientais tornaram-se favoráveis. Segundo Hirsch (1996), células de bactérias dos gêneros Rhizobium, Bradyrhizobium, Sinorhizobium, Mesorhizobium, Azorhizobium e Allorhizobium apresentam grânulos de poli-b-hidroxibutirato, que podem ser catabolizados (Wong \& Evans, 1971) e utilizados como fonte de carbono e energia em situações de estresse. Assim, este mecanismo de adaptação pode contribuir para a sobrevivência e atividade destas bactérias por longos períodos, independentemente da presença de planta hospedeira.

\section{Caracterização cultural de isolados de BNLFN}

Todas as plantas de caupi cultivadas apresentaram nodulação, sendo obtidos destas 420 isolados de BNLFN (Quadro 4) e cerca de $87 \%$ das plantas de feijão nodularam, sendo obtidos 328 isolados. Excetuando as áreas que tinham eucalipto há 16 anos (E16), no campo, e a área de mata fechada sem alteração antrópica (RF), na serra, onde não foram obtidos nódulos, nas demais áreas, obtiveramse números de isolados totais superiores a 14 para feijoeiro e 24 para caupi.

Os isolados de BNLFN obtidos de feijoeiro e caupi foram agrupados de acordo com suas características culturais em 12 e 24 grupos, respectivamente (Quadros 5 e 6). Os isolados de feijoeiro (Figura 1a) foram distribuídos em seis grandes grupos $(60 \%$ de similaridade), sendo o grupo 1 com 258 isolados (79 \%) pertencentes aos grupos morfológicos A, E, $\mathrm{G}$, I e J e a maioria das estirpes-tipo e referência de

Quadro 4. Número total de isolados de bactérias que nodulam leguminosas e fixam $\mathrm{N}_{2}$ (BNLFN), obtidos de caupi e feijoeiro, cultivados em amostras de solo das diferentes áreas de estudo, com seus respectivos índices de diversidade

\begin{tabular}{|c|c|c|c|c|c|}
\hline \multirow{2}{*}{ Área(1) } & \multicolumn{2}{|c|}{ Número de isolados } & \multirow{2}{*}{ Total de isolados } & \multicolumn{2}{|c|}{$\begin{array}{c}\text { Índice de diversidade } \\
\text { H'Shannon-Weaver }\end{array}$} \\
\hline & Feijoeiro & Caupi & & Feijoeiro & Caupi \\
\hline \multicolumn{6}{|l|}{$\mathrm{Campo}^{(2)}$} \\
\hline $\mathrm{RM} 0,5$ & 21 & 28 & 49 & $0^{(4)}$ & 0,88 \\
\hline E3 & 14 & 28 & 42 & 0,41 & 0,80 \\
\hline $\mathrm{AE} 4$ & 19 & 32 & 51 & 1,46 & 1,28 \\
\hline GB10 & 29 & 29 & 58 & $0^{(4)}$ & 1,90 \\
\hline E16 & 0 & 25 & 25 & a.i. ${ }^{(3)}$ & 1,07 \\
\hline BG19 & 26 & 31 & 57 & 0,94 & 1,45 \\
\hline $\mathrm{RF}$ & 24 & 27 & 51 & $0^{(4)}$ & 0,90 \\
\hline Sub total & 133 & 200 & 333 & - & - \\
\hline \multicolumn{6}{|l|}{$\operatorname{Serra}^{(2)}$} \\
\hline RM 0,5 & 18 & 26 & 44 & 1,65 & 0,32 \\
\hline FGb2 & 30 & 30 & 60 & $0^{(4)}$ & 1,90 \\
\hline GB6 & 20 & 25 & 45 & 0,20 & 1,43 \\
\hline M10 & 26 & 28 & 54 & $0^{(4)}$ & 1,50 \\
\hline B14 & 30 & 28 & 58 & 1,31 & 1,72 \\
\hline E16 & 49 & 30 & 79 & 1,42 & 1,33 \\
\hline M18 & 22 & 29 & 51 & $0^{(4)}$ & 1,49 \\
\hline $\mathrm{RF}$ & 0 & 24 & 24 & a.i. ${ }^{(3)}$ & 1,18 \\
\hline Sub total & 195 & 220 & 415 & - & - \\
\hline
\end{tabular}


espécies do gênero Rhizobium, além de $S$. medicae e $S$. terangae; o grupo 2 apresentou 13 isolados (4\%) dos grupos morfológicos B e $\mathrm{F}$ e a maioria das estirpes-tipo de espécies do gênero Sinorhizobium e das espécies Rizobium galegae e Allorhizobium undicola; o grupo 3 englobou 14 isolados (4\%) pertencentes ao grupo morfológico $\mathrm{H}$ e a maioria das estirpes-tipo de espécies do gênero Mesorhizobium; o grupo 5 foi formado por 11 isolados (3\%) dos grupos morfológicos C, L e M e estirpes-tipo de espécies do gênero Bradyrhizobium, e o grupo 6, por 32 isolados (10 \%) do grupo morfológico D e estirpe-tipo Azorhizobium caulinodans. O grupo 4 conteve apenas a estirpe-tipo $M$. huakuii. A maioria dos isolados de feijoeiro apresentou maior similaridade às estirpes pertencentes a espécies dos gêneros Rhizobium e Sinorhizobium, de crescimento rápido e caráter acidificante.

Para o caupi (Figura 1b), a $60 \%$ de similaridade, formaram-se oito grandes grupos, sendo o grupo 1 com 293 isolados (70 \%) pertencentes aos grupos morfológicos A, B, D, H, P, Q, R, V e Z1 e estirpestipo e referência de espécies do gênero Bradyrhizobium; o grupo 2 englobou 11 isolados (3\%) pertencentes aos grupos morfológicos I, M e U e estirpe tipo $M$. huakuii; o grupo 3 foi representado apenas pela estirpe-tipo de A. caulinodans, ou seja, nenhum isolado assemelhou-se a esta estirpe; já o grupo 4 formou um grupo a parte com 46 isolados (11\%) dos grupos morfológicos C, L, N e S; e grupo 5 apresentou 3 isolados $(<1 \%)$ exclusivamente do grupo morfológico O; o grupo 6 apresentou 4 isolados (1\%) dos grupos morfológicos X e Z e estirpes-tipo da maioria das espécies do gênero Mesorhizobium; o grupo 7 foi formado de 34 isolados (8\%) pertencentes aos grupos morfológicos $\mathrm{E}$ e $\mathrm{G}$ e estirpes- tipo da maioria de espécies do gênero Sinorhizobium e das espécies Rhizobium galegae e Allorhizobium undicola e, finalmente, o grupo 8 conteve 29 isolados (7 \%) pertencentes aos grupos morfológicos F, J e T e estirpes-tipo na maioria de espécies do gênero Rhizobium, S. medicae e S. terangae.

Resumindo: o caupi, portanto, nodulou predominantemente com BNLFN de características culturais semelhantes às das estirpes tipo de espécies do gênero Bradyrhizobium, de crescimento lento e de caráter alcalinizante, embora os isolados estivessem mais uniformemente distribuídos nos demais gêneros, quando comparados ao feijoeiro. Este resultado confirma a menor especificidade do caupi e concorda com aqueles encontrados por Lewin et al. (1987), Martins et al. (1997) e Pereira (2000), os últimos avaliando a diversidade fenotípica de BNLFN, em outros ecossistemas, utilizando o caupi como espécie de planta-isca.

\section{Índice de diversidade de BNLFN}

Houve efeito das estratégias de reabilitação na diversidade fenotípica de BNLFN, com comportamentos diferenciados entre as espécies de plantas-isca utilizadas (Quadro 4). O caupi apresentou, de modo geral, maiores índices de diversidade de BNLFN e possibilitou melhor discriminação entre as áreas mineradas, em relação ao tempo de reabilitação, do que o feijoeiro. Isto demonstra o maior potencial de utilização desta espécie de planta-isca em estudos de diversidade de BNLFN em solos minerados. Verificou-se ausência de diversidade de BNLFN de feijoeiro em várias áreas do campo e serra, mostrando, portanto, menor promiscuidade desta espécie para formar simbiose com populações nativas destes solos, em relação ao

Quadro 5. Grupos fenotípicos culturais de bactérias que nodulam leguminosas e fixam $\mathrm{N}_{2}(\mathrm{BNLFN})$ e número de isolados de feijoeiro, classificados por grupo, no campo e serra

\begin{tabular}{|c|c|c|c|c|c|c|c|}
\hline \multirow{2}{*}{ Grupo } & \multicolumn{5}{|c|}{ Caracterização cultural dos isolados ${ }^{(1)}$} & \multicolumn{2}{|c|}{ Total de isolados } \\
\hline & 1 & 2 & 3 & 4 & 5 & Campo & Serra \\
\hline $\mathrm{A}$ & $2-3$ & 2,5 & Ácido & Baixa-alta & Amarela & 111 & 127 \\
\hline $\mathrm{B}$ & 3 & 2,0 & Ácido & Seca & Branca & 4 & 7 \\
\hline $\mathrm{C}$ & 6 & 2,0 & Alcalino & Seca & Branca & 2 & 5 \\
\hline $\mathrm{D}$ & 3 & 2,0 & Neutro & Seca & Branca & 2 & 30 \\
\hline $\mathrm{E}$ & 3 & 3,0 & Ácido & Baixa-alta & Branca & 11 & 0 \\
\hline $\mathrm{F}$ & $<2$ & 2,0 & Ácido & Baixa-média & Branca & 2 & 0 \\
\hline $\mathrm{G}$ & $2-3$ & 2,5 & Neutro & Baixa-média & Branca & 1 & 4 \\
\hline $\mathrm{H}$ & $3-4$ & 1,5 & Ácido & Seca & Amarela & 0 & 14 \\
\hline I & 3 & $>4,0$ & Ácido & Média & Amarela & 0 & 1 \\
\hline $\mathrm{J}$ & 3 & 3,5 & Neutro & Alta & Amarela & 0 & 3 \\
\hline $\mathrm{L}$ & 6 & $<1,0$ & Alcalino & Seca & Amarela & 0 & 2 \\
\hline M & 6 & 1,0 & Alcalino & Seca & Branca & 0 & 2 \\
\hline
\end{tabular}

(1) 1 (tempo, em dias, para visualização das colônias), 2 (diâmetro médio das colônias, em mm), 3 (modificação do $\mathrm{pH}$ do meio de cultura 79), 4 (produção de goma) e 5 (coloração das colônias). 
Quadro 6. Grupos fenotípicos culturais de bactérias que nodulam leguminosas e fixam $\mathrm{N}_{2}(\mathrm{BNLFN})$ e número de isolados de caupi, classificados por grupo, no campo e na serra

\begin{tabular}{|c|c|c|c|c|c|c|c|}
\hline \multirow{2}{*}{ Grupo } & \multicolumn{5}{|c|}{ Caracterização cultural dos isolados ${ }^{(1)}$} & \multicolumn{2}{|c|}{ Total de isolados } \\
\hline & 1 & 2 & 3 & 4 & 5 & Campo & Serra \\
\hline $\mathrm{A}$ & $6-10$ & 1,5 & Alcalino & Seca & Branca & 9 & 8 \\
\hline $\mathrm{B}$ & $6-10$ & 2,0 & Alcalino & Baixa-média & Branca & 118 & 109 \\
\hline $\mathrm{C}$ & $6-10$ & 2,5 & Neutro & Baixa-alta & Branca & 10 & 23 \\
\hline $\mathrm{D}$ & $6-10$ & $>4,0$ & Alcalino & Média-alta & Branca & 7 & 2 \\
\hline $\mathrm{E}$ & $2-3$ & 2,0 & Ácido & Média-alta & Amarela & 6 & 18 \\
\hline $\mathrm{F}$ & $2-3$ & $>4,0$ & Ácido & Alta & Amarela & 15 & 5 \\
\hline $\mathrm{G}$ & $2-3$ & 2,0 & Neutro & Média-alta & Amarela & 8 & 2 \\
\hline $\mathrm{H}$ & $4-6$ & 1,5 & Alcalino & Seca & Branca & 2 & 2 \\
\hline $\mathrm{I}$ & $4-6$ & 4,0 & Alcalino & Alta & Amarela & 4 & 0 \\
\hline $\mathrm{J}$ & $4-6$ & $>4,0$ & Ácido & Alta & Amarela & 1 & 0 \\
\hline $\mathrm{L}$ & $6-10$ & 1,0 & Ácido & Média-alta & Branca & 4 & 0 \\
\hline M & $4-6$ & 3,5 & Neutro & Média-alta & Amarela & 1 & 1 \\
\hline $\mathrm{N}$ & $6-10$ & 2,0 & Neutro & Média-alta & Amarela & 4 & 3 \\
\hline $\mathrm{O}$ & $6-10$ & $<1,0$ & Ácido & Seca & Amarela & 2 & 1 \\
\hline $\mathrm{P}$ & $6-10$ & 2,0 & Alcalino & Média-alta & Branca & 2 & 11 \\
\hline $\mathrm{Q}$ & $6-10$ & 2,5 & Alcalino & Baixa-média & Amarela & 0 & 13 \\
\hline $\mathrm{R}$ & $6-10$ & $<1,0$ & Alcalino & Baixa-média & Amarela & 7 & 0 \\
\hline $\mathrm{S}$ & $6-10$ & 2,0 & Ácido & Média & Branca & 0 & 2 \\
\hline $\mathrm{T}$ & $4-6$ & 4,0 & Ácido & Alta & Branca & 0 & 8 \\
\hline $\mathrm{U}$ & $4-6$ & 2,0 & Alcalino & Baixa-média & Amarela & 0 & 5 \\
\hline $\mathrm{V}$ & $4-6$ & $>4,0$ & Alcalino & Média & Branca & 0 & 2 \\
\hline $\mathrm{X}$ & $4-6$ & 1,0 & Ácido & Seca & Amarela & 0 & 2 \\
\hline $\mathrm{Z}$ & $4-6$ & 2 & Ácido & Média & Branca & 0 & 2 \\
\hline $\mathrm{Z} 1$ & $4-6$ & $1-2$ & Alcalino & Seca & Branca & 0 & 1 \\
\hline
\end{tabular}

(1) 1 (tempo, em dias, para visualização das colônias), 2 (diâmetro médio das colônias, em mm), 3 (modificação do pH do meio de cultura 79), 4 (produção de goma) e 5 (coloração das colônias).

caupi. A diferença de comportamento da espécie vegetal utilizada como planta-isca de BNLFN foi também demonstrada por Handley et al. (1997), Pereira (2000) e Moreira \& Pereira (2001), autores estes que indicam a utilização de grande número de plantas-isca, em estudos de diversidade destes microrganismos.

Para o caupi, a maior diversidade foi obtida em algumas áreas revegetadas com leguminosas (Quadro 4). Dentre essas, no ambiente campo, a área revegetada com capim-gordura, em sucessão há 10 anos (GB10), e na que apresentava bracatinga com sub-bosque bem desenvolvido com 19 anos de reabilitação (BG19) mostraram tal comportamento. Já na serra, as áreas revegetadas com feijão-guandu, braquiária e espécies arbóreas nativas há dois anos (FGb2) e bracatinga com vegetação rasteira e arbustiva há 14 anos (B14) foram as que proporcionaram maior diversidade de BNLFN.

Apesar do baixo índice de diversidade calculado para a área com espécies graminóides e arbustivas sem alteração antrópica (RF), no campo, os menores valores desse foram obtidos na área com plantio homogêneo de eucalipto (E3) há três anos e nas áreas recém-mineradas, tanto do campo quanto da serra, evidenciando o efeito negativo da mineração sobre a diversidade fenotípica de BNLFN. A baixa diversidade relativa destes microrganismos nas áreas de referência (RF) do campo e da serra (RF) pode estar associada à menor diversidade de espécies leguminosas e à maior presença de serapilheira.

Embora a revegetação que utilizava eucalipto em plantio adensado e homogêneo, no campo, tenha apresentado menor influência nas variáveis relacionadas com a nodulação (número, matéria fresca e atividade de nódulos), verificou-se que nas áreas com plantio homogêneo de eucalipto (E3), no campo, e na área revegetada com eucalipto (E16), na serra, os índices de diversidade de BNLFN oscilaram, sendo inferiores e superiores à referência sem alteração antrópica do campo, respectivamente. Em áreas revegetadas com eucalipto, na serra (E16), pelo fato de ter sido utilizado maior espaçamento, houve a formação de um sub-bosque de grande riqueza vegetal, o qual pode ter contribuído para maior recuperação da diversidade de BNLFN, após 16 anos de reabilitação, com índices superiores aos 
(a) Feijoeiro

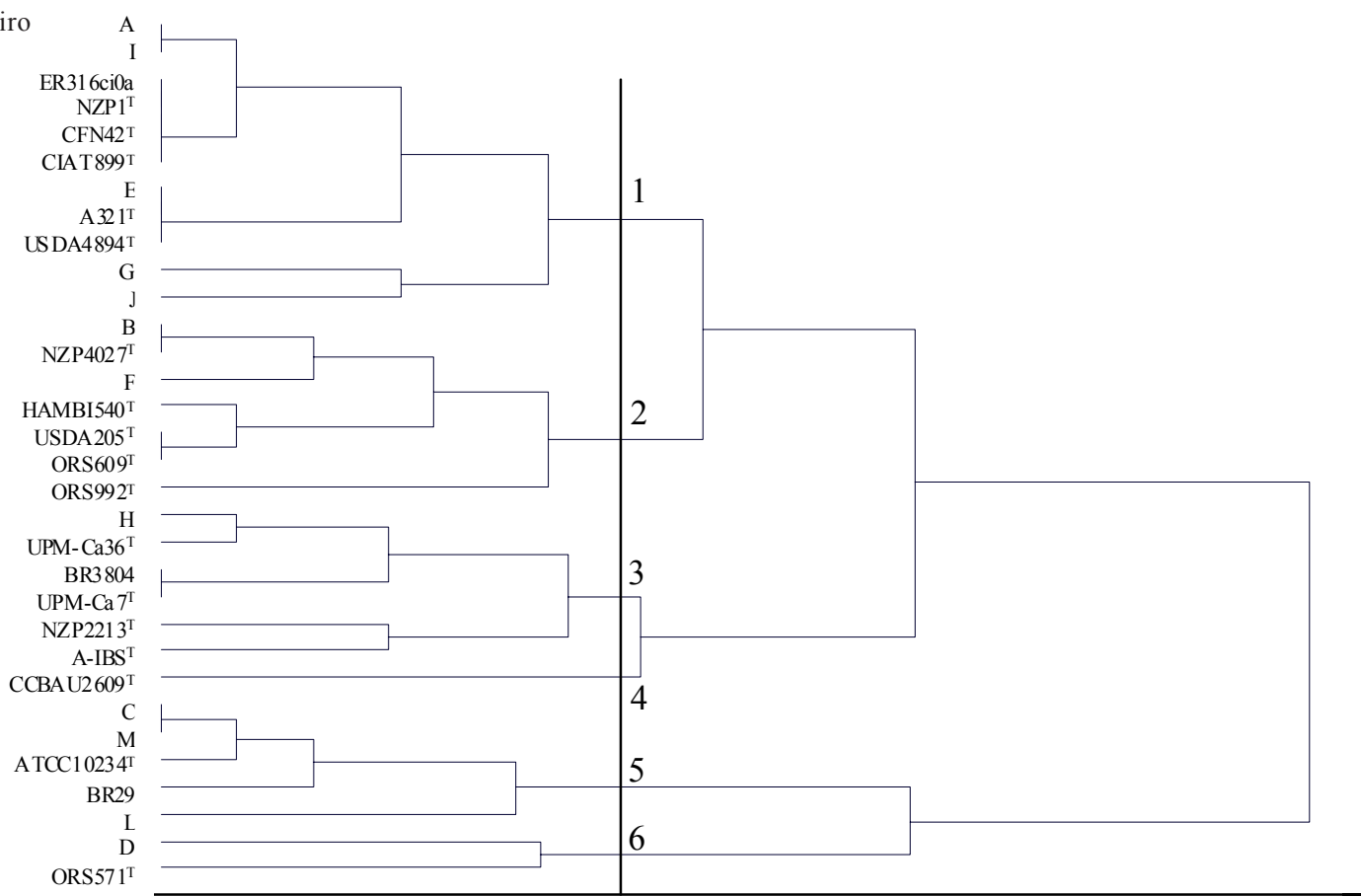

(b) Caupi

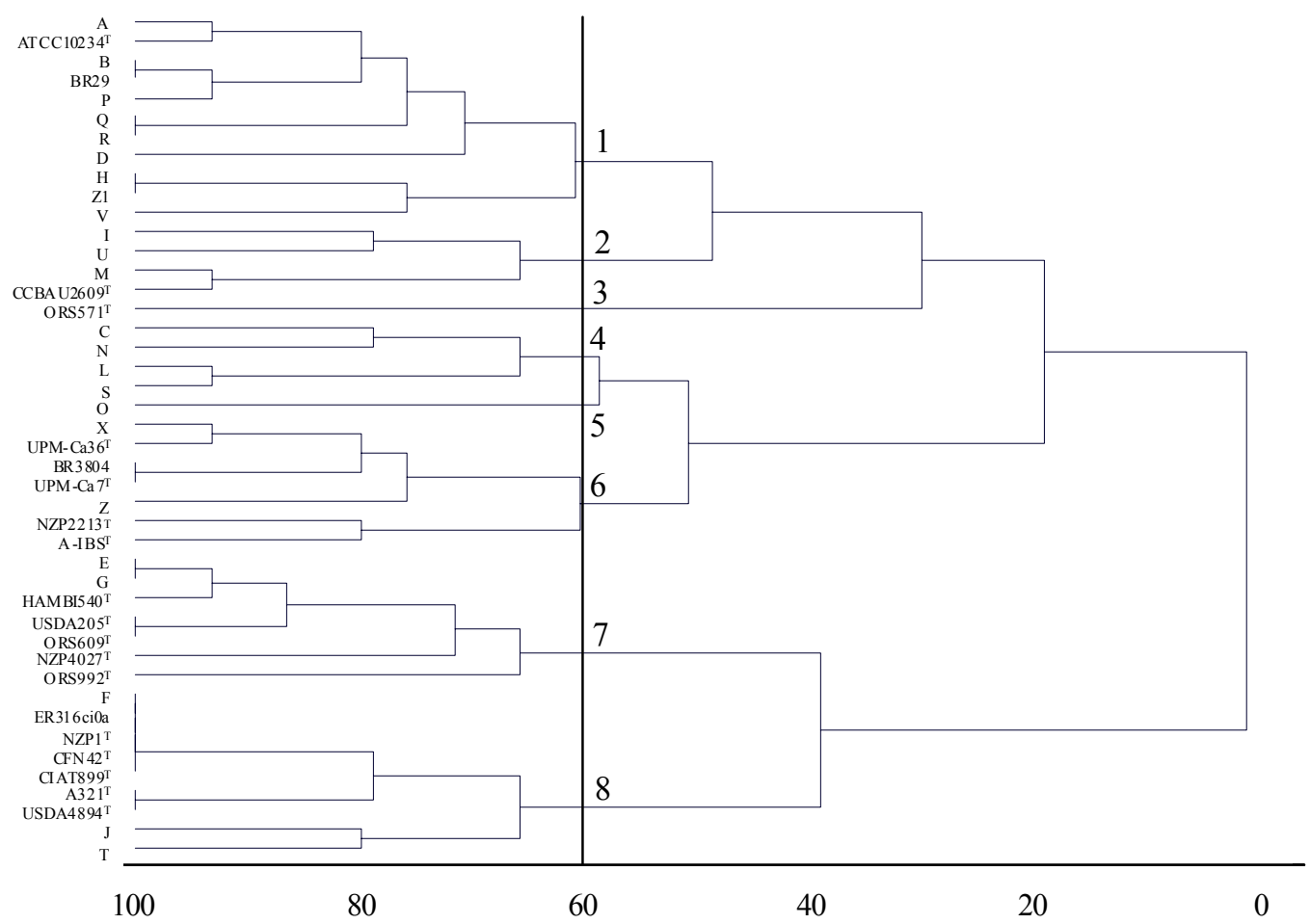

Figura 1. Dendrogramas de similaridade, construídos de acordo com os grupos fenotípicos culturais: a grupos fenotípicos de A, B, C,... M, para os isolados de bactérias nodulíferas de feijoeiro e b - (A, B, $\mathrm{C}, . . \mathrm{Z}, \mathrm{Z1}$ ) de isolados de bactérias nodulíferas de caupi, ambos cultivados em amostras de solos de áreas de mineração, e com as estirpes-tipo e referência: ER 316 ci0a (Rhizobium leguminosarum bv. phaseoli), NZP 1 (R. leguminosarum trifolii), CFN $42^{\mathrm{T}}$ (R. etli), CIAT $899^{\mathrm{T}}$ (R. tropici), HAMBI $540^{\mathrm{T}}(\boldsymbol{R}$. galegae bv. orientalis), NZP $4027^{\mathrm{T}}$ (Sinorhizobium meliloti), USDA $205^{\mathrm{T}}$ (S. fredii cv. fredii), A321 ${ }^{\mathrm{T}}(S$.

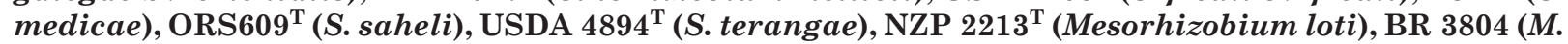
plurifarium), UPM-Ca7 ${ }^{\mathrm{T}}$ (M. ciceri), CCBAU $2609^{\mathrm{T}}$ (M. huakuii), A-IBS ${ }^{\mathrm{T}}$ (M. tianshinense), UPM-Ca36 ${ }^{\mathrm{T}}$ (M. mediterraneum), ATCC10324 ${ }^{\mathrm{T}}$ (Bradyrhizobium japonicum), BR29 (B. elkanii), ORS 571 (Azorhizobium caulinodans), ORS 992T (Allorhizobium undicola). Descrição dos grupos fenotípicos culturais nos quadros 5 e 6. 
das referências que não sofreram alteração antrópica (RF), indicando uma relação direta entre diversidade acima e abaixo da superfície do solo.

Estes resultados mostram que o eucalipto pode apresentar efeitos contraditórios na nodulação e diversidade de BNLFN, dependendo da riqueza vegetal formada no seu sub-bosque, quando na reabilitação de solos de áreas de mineração.

Estudos que exploram a diversidade de gruposchave de microrganismos são importantes, pois, além de fornecerem um indicativo do efeito de diferentes métodos utilizados para reabilitação de áreas degradadas sobre a diversidade destes grupos, possibilitam, ainda, isolamento de estirpes promissoras para usos potenciais diversos. Neste contexto, em um estudo realizado em solos de áreas de mineração de cassiterita na região Amazônica, utilizando soja, feijoeiro, mucuna-preta, guandu, crotalária e siratro como plantas isca, foram obtidas estirpes de BNLFN competitivas e eficientes, quando comparadas com as estirpes comerciais (Sanches, 2002).

Motta (2002), estudando 12 isolados da plantaisca caupi, oriundos das populações avaliadas no presente estudo, encontrou resultados positivos na inoculação de caupi em vasos Leonard. Dez estirpes, das doze testadas, foram altamente eficientes produzindo matéria seca da parte aérea da planta similar à da testemunha, que recebeu adubação nitrogenada, e as plantas apresentaram uma produção de matéria seca da parte aérea bem superior à das plantas inoculadas com a estirpe comercial SEMIA 6145, recomendada pela RELARE (2000).

Como há indicativos de boa sobrevivência destas estirpes no seu habitat de origem, como relatado anteriormente, estas são de grande interesse para estudos posteriores de inoculação em espécies vegetais para a revegetação destas áreas, objetivando enriquecer o solo com nitrogênio e matéria orgânica e acelerar a sucessão vegetal nestes ambientes.

\section{CONCLUSÕES}

1. Em estudos de nodulação, eficiência e diversidade fenotípica de bactérias nodulíferas de leguminosas e fixadoras de $\mathrm{N}_{2}$, em áreas de mineração de bauxita em reabilitação, o caupi é mais indicado que o feijoeiro por recuperar maior diversidade destes microrganismos.

2. O impacto negativo da mineração é maior na diversidade fenotípica cultural de bactérias nodulíferas fixadoras de $\mathrm{N}_{2}$ do que na nodulação das plantas-isca utilizadas, mostrando ser o primeiro parâmetro o mais indicado para avaliar a eficiência da reabilitação.
3. A revegetação, independentemente da idade, aumenta a diversidade de bactérias nodulíferas de leguminosas e fixadoras de $\mathrm{N}_{2}$, em relação às áreas recém-mineradas e mesmo em relação às áreas de referência.

4. Maior diversidade de bactérias nodulíferas de leguminosas e fixadoras de $\mathrm{N}_{2}$ foi encontrada em áreas revegetadas com as leguminosas bracatinga e feijão-guandu.

\section{LITERATURA CITADA}

ANDRADE, D.S. \& HAMAKAWA, P.J. Estimativa do número de células de rizóbio no solo e inoculantes por infecção em planta. In: HUNGRIA, M. \& ARAÚJO, R.S., eds. Manual de métodos empregados em estudos de microbiologia agrícola. Brasília, Empresa de Pesquisa Agropecuária Brasileira, 1994. p.63-94.

DIAS, L.E. \& GRIFFITH, J.J. Conceituação e caracterização de áreas degradadas. In: DIAS, L.E. \& MELLO, J.W.V., eds. Recuperação de áreas degradadas. Viçosa, Universidade Federal de Viçosa, 1998. p.1-7.

DILWORTH, M.J. Acetylene reduction by nitrogen-fixing from Clostridium pasteurinum. Biochem. Biophica Acta, 127:285294, 1966.

EVERITT, B.S. Cluster analysis. New York, John Wiley, 1993. $170 \mathrm{p}$.

FRANCO, A.A. \& FARIA, S.M. The contribution of $\mathrm{N}_{2}$-fixing tree legumes to land reclamation and sustainability in the tropics. Soil Biol. Biochem., 29:897-903, 1997.

FRED, E.B. \& WAKSMAN, S.A. Laboratory manual of general microbiology. New York, McGraw-Hill Book Company, 1928. 143p.

HANDLEY, B.A.; HEDGES, A.J. \& BERINGER, J.E. Importance of host plants for detecting the population diversity of Rhizobium leguminosarum biovar viciae in soil. Soil Biol. Biochem., 30:241-249, 1997.

HIRSCH, P.R. Population dynamics of indigenous and genetically modified rhizobia in the field. New Phytol., 133:159-171, 1996.

JORDAN, D.C. Rhizobiaceae Conn 1938. In: Bergey's manual of systematic bacteriology. London, Williams and Wilkins, 1984. v.1, p.234-244.

LEWIN, A.; ROSENBERG, C.; MEYER, Z.A.; WONG, C.H.; NELSON, L.; MANEN, J.F.; STANLEY, J.; DOWLING, D.N.; DÉNARIE, J. \& BROUGHTON, W.J. Multiple hostspecificity loci of the broad host-range Rhizobium sp. NGR234 selected using the widely compatible legume Vigna unguiculata. Plant Molecular Biol., 8:447-459, 1987.

MARTINS, L.M.V.; NEVES, M.C.P. \& RUMJANEK, N.G. Growth characteristics and symbiotic efficiency of rhizobia isolated from cowpea nodules of the north-east Region of Brazil. Soil Biol. Biochem., 29:1005-1010, 1997.

MELLONI, R.; SIQUEIRA, J.O. \& MOREIRA, F.M.S. Fungos micorrízicos arbusculares em solos de áreas de mineração de bauxita em reabilitação. Pesq. Agropec. Bras., 38:267$276,2003$. 
MELLONI, R.; NÓBREGA, R.S.A.; MOREIRA, F.M.S. \& SIQUEIRA, J.O. Densidade e diversidade fenotípica de bactérias diazotróficas endofíticas em solos de mineração de bauxita, em reabilitação. R. Bras. Ci. Solo, 28:85-93, 2004.

MELO, V.A.; GRIFFITH, J.J.; JÚNIOR, P.D.M.; SILVA, E.; SOUZA, A.L \& GUEDES, M.C. Efeito dos poleiros artificiais na dispersão de sementes por aves. R. Árvore, 24:235-240, 2000.

MOREIRA, F.M.S. Caracterização de estirpes de rizóbio isoladas de espécies florestais pertencentes a diversos grupos de divergência de Leguminosae introduzidas ou nativas da Amazônia e Mata Atlântica. Rio de Janeiro, Universidade Federal Rural do Rio de Janeiro, 1991. 160p. (Tese de Doutorado)

MOREIRA, F.M.S.; GILLIS, M.; POT, B.; KERSTERNS, K. \& FRANCO, A.A. Characterization of rhizobia isolated from different divergence groups of tropical Leguminosae by comparative polyacrylamide gel electrophoresis of their total proteins. Syst. Appl. Microb., 16:135-146, 1993.

MOREIRA, F.M.S. \& PEREIRA, E.G. Microsymbionts: rhizobia. In: SWIFT, M. \& BIGNELL, D., eds. Standard methods for assessment of soil biodiversity and land use practice. Bogor: ICRAF, 2001. p.19-24. (ASB Lecture Note 6B)

MOTTA, J.S. Diversidade fenotípica e eficiência simbiótica de estirpes de Bradyrhizobium sp. isoladas de áreas de mineração de bauxita reabilitadas. Lavras, Universidade Federal de Lavras, 2002. 43p. (Tese de Mestrado)
PEREIRA, E.G. Diversidade de rizóbios isolados de diferentes sistemas de uso da terra na Amazônia. Lavras, Universidade Federal de Lavras, 2000. 93p. (Tese de Doutorado)

REUNIÃO DA REDE DE LABORATÓRIOS PARA RECOMENDAÇÃO, PADRONIZAÇÃO E DIFUSÃO DE TECNOLOGIA DE INOCULANTES MICROBIOLÓGICOS DE INTERESSE AGRÍCOLA- RELARE, 9., 2000. www.relare.org.br

SANCHES, A.C. Adubação fosfatada e inoculação de leguminosas com Bradyrhizobium na recuperação de solos degradados pela mineração de cassiterita na região Amazônica. Jaboticabal, Universidade Estadual Paulista, 2002. 96p. (Tese de Doutorado)

SHANNON, C.E. \& WEAVER, W. The mathematical theory of communication. Urbana, University of Illinois Press, 1949.

SIQUEIRA, J.O.; MOREIRA, F.M.S.; GRISI, B.M.; HUNGRIA, M. \& ARAUJO, R.S. Microrganismos e processos biológicos do solo: perspectiva ambiental. Brasília, Empresa de Pesquisa Agropecuária Brasileira, 1994. 142p.

STATISTICA. Statistic Analysis. Versão 5.0. 1995.

WONG, P.P. \& EVANS, H.J. Poly-b-hydroxybutyrate utilization by soybean (Glycine max Merr.) nodules and assessment of its role in maintenance of nitrogenase activity. Plant Physiol., 47:750-755, 1971.

ZONTA, E.P.; MACHADO, A.A. \& SILVEIRA Jr., P. Sistemas de análise estatística para microcomputadores (SANEST). Pelotas, Universidade Federal de Pelotas, 1984. 151p. 